ELK

Asia Pacific Journals

www.elkjournals.com

\title{
SEASONALITY AND ASYMMETRIC CONDITIONAL VOLATILITY: AN ANALYSIS OF INDIAN VIX
}

\begin{tabular}{|c|}
\hline Dr. Jyothi Chittineni \\
Sr. Asst. Professor (Finance) \\
Vignana Jyothi Institute of Management \\
9848779770 \\
jyothi.kurra@gmail.com \\
\hline
\end{tabular}

\begin{abstract}
The study aims to understand the behavior of Indian Implied Volatility Index (Indian VIX) in terms of its seasonal anomalies, like day-of-the-week effect and month-of-the-year effect. The study examines the effect of options expiration dates on expected market volatility. The study also investigates the asymmetric relationship between Indian Implied Volatility and its underlying series Nifty 50 index returns. The empirical result confirms that the Indian VIX holds seasonal anomalies. The results explain that there is a significant positive Monday effect on expected market volatility. The month-of-the-year results reported that the corporate announcements have a significant impact on Indian VIX. The Regression estimates supported a strong negative correlation between Indian VIX and stock returns. The results of the study are important for portfolio managers, volatility traders and risk managers to price the options and to understand the exit and entry timing in the equity markets.
\end{abstract}

Keywords: Indian Implied Volatility index, seasonal anomalies, asymmetric relation, Nifty stock returns.

JEL Classification: G 10, G11, G14.

\section{INTRODUCTION}

The Implied Volatility index measures the market participant's expectation about future market volatility over the near term. The Implied volatility index tends to rise when the market moves steeply upwards or downwards. The implied volatility index value declines when market subsides. The Chicago Board of Options Exchange first introduced implied volatility index based on the S\&P 100 index options in the year 1993. The Implied Volatility Index was proposed by Whaley (1995). This methodology was revised in 2003 and the new implied volatility index was based on the S\&P 500 index options. This VIX indicates the investor's perceptions about the future market volatility for next 30 day calendar period. It is widely known as investors' fear gauge (Whaley 2000) 


\section{INDIAN IMPLIED VOLATILITY INDEX:}

Indian Implied volatility index (IVIX, henceforth) is calculated based on the NIFTY index options. It is calculated by taking the weighted average sum of At-The-Money and Out-of-The-Money put and call options close to maturities across available strikes. Indian Implied volatility index (IVIX henceforth) indicates the investor's perception about the NIFTY index volatility over the next 30 calendar days. Higher the IVIX value, higher the expected market volatility and lower the IVIX value, lower the expected market volatility. From the volatility index, investors can (i) understand the expected volatility of the underlying stock index returns, (ii) understand the market agent's perceptions about the market direction and (iii) frame hedge strategies to insure their portfolio against the future volatility. The study on Indian Implied volatility index behavior is important for fund managers, volatility traders and retail investors to hedge their portfolios against risk.

One section of literature on Indian Implied volatility focuses on its information content, its negative correlation with its underlying market index and its forecasting ability about the future jumps. Another section focuses on comparing the efficiency with other realized volatility measures like ARCH and GARCH models. Very few studies focus on understanding the behavior of VIX in terms of its seasonality and understanding
Indian VIX behavior during the options expiry dates. This paper bridges the gap through an attempt to understand the seasonal anomalies like the day-of-the-week effect, the month-of-theyear effect and Indian VIX behavior during the options expiry dates and its inter-temporal relation with its underlying series NSE S\&P 50 returns series.

\section{REVIEW OF LITERATURE:}

There is a good amount of literature available on seasonal effect on stock returns series. The literature documented the seasonality of stock returns (Cross 1973; French 1980; Gibbons, Hess 1981; Lakonishok, Levi 1982; Stambaugh 1984; Jaffe, Westerfield 1985; Schwert 1989, 1990; Aggarwal, Rivoli 1989; Fleming et al. 1995; Balaban et al. 2001). These studies analyzed dayof-the-week effect and month-of-the year effect. The results reported that there is a significant negative correlation during Mondays and Fridays and a correlation coefficient of these two days is high compared to other days. The research also reported month-of-the-year anomalies (Eg: Rozeff, Kinney 1976; Keim 1983; Gultekin, M. N., Gultekin, N. B. 1983; Tong 1992; Pandey 2002). Results found that there is a significant January effect, which is due to tax motivated trading. The study conducted by Fleming et al. (1995) reported day-of-the-weak effect and the effect of options expiration dates on the VIX 
series; this paper also documented inverse and asymmetric relation volatility index and underlying stock index return series. A study by Dowling and Muthuswamy (2005) on Australian Implied Volatility Index (AVIX) evidences strong seasonal anomalies and strong intertemporal asymmetric relation between AVIX and its stock index returns. Shaikh, P Padhi (2014) conducted a study on Indian implied volatility index to understand its behavior. These studies reported a significant Monday effect. Monday effect explains the rise in expected volatility during the market opening days and fall from Wednesday to Friday.

Whaley (2009) in his study 'understanding the VIX' reported that the change in the VIX value increases at a higher rate when the market falls than the market rise. Badshah (2011) tested the asymmetric return-volatility relation in panel framework and his test results revealed a significant negative relationship between stock return and its implied volatility index. Authors like Skiadopoulos (2004); Giot (2004); Hibbert (2008); Frijns, Tallau, \& Tourani-Rad (2013) examined the relationship between stock returns and implied volatility index. These studies reported a significant negative relation between returns and the implied volatility index. The study also concluded that the negative returns have more impact on implied volatility change than the positive returns. These empirical evidences confirm that the average market volatility responds asymmetrically to the positive and negative returns.

In the Indian context, Shaikh (2015) investigated the contemporaneous inter-temporal relation between IVIX and stock returns. The results revealed that there exists asymmetry between India VIX and Stock returns, but the magnitude is different. Dhanaiah (2012) used OLS regression model and results revealed the asymmetric relation between stock returns and IVIX change.

There is quite a good amount of literature available on the seasonality of stock returns series but very limited studies are available based on implied volatility index and its seasonal anomalies. Hence, the study on Indian Implied volatility is important for the volatility traders, investors and fund managers.

\section{DATA AND EMPIRICAL MODELS:}

Closing Indian VIX data and NSE S\&P 50 stock index values are retrieved from National Stock Exchange of India (NSE) on a daily basis from $2^{\text {nd }}$ March 2009 to $27^{\text {th }}$ March 2018- there are 2249 trading days in that period.

Change in Indian Implied Volatility Index is measured as

$$
\Delta I V I X=I V I X_{t}-I V I X_{t-1}
$$


Stock index returns are calculated as $R_{t}=$ $\ln \left(\frac{R_{t}}{R_{t-1}}\right)$

Day-of-the-week anomalies are estimated using Autoregressive dummy variable ordinary least squares (AR-DOLS) and the model is expressed as follows:

$R_{t}=\sum_{i=1}^{5} \alpha_{i} D_{i t}+\gamma R_{t-1}+\varepsilon_{t}$

Where,

If the day is Monday then, $D_{i t}=1$ otherwise $D_{i t}$ $=0$;

$i=1$ : Monday, Tuesday, Wednesday, Thursday and Friday.

If day-of-the-week anomalies exist for Indian Implied volatility index then the slope of the equation $\alpha_{i}$ value should be statistically different from zero, if the slope of Monday is positive and significant that confirms the day-of-the-week effect in the Indian VIX returns series.

One more term added to the above equation (3) to measure the Indian VIX behavior near the onemonth options expiration is expressed as follows:

$R_{t}=\sum_{j=-2}^{2} \delta_{j} D_{j t}+\sum_{i=1}^{5} \alpha_{i} D_{i t}+\gamma R_{t-1}+\varepsilon_{t^{----}}$

Where, $D_{j t}$ expiration day, i.e. last Thursday of the month.

On the options expiry date, investors are more certain about the market condition and hence, the slope of the equation $\delta_{j}$ should be negative and significant.

The following regression model is used to estimate the month-of-the-year effect on the Indian Implied Volatility Index:

$R_{t}=\sum_{k=1}^{12} \varphi_{k} D_{k t}+\gamma R_{t-1}+\varepsilon_{t}$

Where, $D_{k t}=\mathrm{I}$, January

$D_{k t}=0$, otherwise

$\mathrm{K}=$ January, February, March, April, May, June, July, August, September, October, November and December.

If Indian VIX exhibits any patterns based on the month then the slope of the equation $\varphi_{k}$ should be different from zero and remains significant.

The ARCH-test and Autocorrelation reported the significant presence of Heteroscedasticity and Autocorrelation in the residuals hence, the regression models estimated by using ARGARCH $(1,1)$ specification. The AR-GARCH $(1,1)$ model expresses as follows:

$\sigma_{t}^{2}=\pi_{0}+\pi_{1} \varepsilon_{t}^{2}+\pi_{2} \sigma_{t}^{2}$

Where, $\pi_{1}>0, \pi_{2}>0, \pi_{1}+\pi_{2} \leq 1$

Fleming (1995) measured the linear and intertemporal risk-return relationship for changes in CBOE VIX and stock market returns. Fleming proposed multivariate regression model to test inter-temporal contemporaneous risk returns 
ISSN 2349-2325 (Online); DOI: 10.16962/EAPJFRM/issn. 2349-2325/2015; Volume 9 Issue 2 (2018)

relationship. In this model, he regressed the change in VIX value on two leads, two lags, contemporaneous stock returns and the absolute value of contemporaneous nifty 50 returns. This model has been adopted by many researchers Shaikh \& Padhi (2015) to test the inter-temporal relationship between risk and returns. To estimate the co-movements of the stock market returns and Indian implied Volatility index the following Multivariate Regression model is employed.

$$
\begin{aligned}
\Delta I V I X=\alpha+ & \emptyset_{-2} R_{t-2}+\emptyset_{-1} R_{t-1}+\emptyset_{0} R_{t} \\
& +\emptyset_{t+1} R_{t+1}+\emptyset_{t+2} R_{t+2} \\
& +\emptyset_{|a b s|}\left|R_{t}\right|+\mu_{t}
\end{aligned}
$$

The negative slope of the equation signifies that for negative stock returns the volatility index increases and the positive slope indicates that volatility moves in the direction of stock returns irrespective of positive or negative stock returns.

\section{Descriptive statistics of Indian VIX:}

Table 1 reports descriptive statistics for Indian VIX and VIX returns series. The mean of IVIX close is 20.13 and VIX returns series is -0.07321 . The volatility of IVIX and IVIX returns are 7.6133 and 0.0693 respectively. The autocorrelation and Auto-Regressive Conditional Heteroscedasticity are presented up to three lags. There are evidences for autocorrelation and heteroscedasticity in the residuals. Hence, AR term is added in the model to resolve autocorrelation problem and to control the heteroscedasticity in the residuals $\mathrm{GARCH}$ framework is used. (Ref Table 1)

\section{EMPIRICAL ANALYSIS:}

The empirical analysis of Indian VIX for its seasonal anomalies and its contemporaneous correlation with NSE 50 stock returns was estimated by using equation (4) and the results are presented in Table 2 . This equation estimated the day-of-the-week effect and options expiration effect on Indian Implied Volatility Index. The results on AR-GARCH and AR-DOLS are presented. The result shows significant Monday effect and negative options expiry effect. The slope coefficient (0.0358) for Monday is significant at $1 \%$ significance level and slope coefficients are not significant for other days. The results found that there is a significant Monday effect on VIX change data and did not find any significant effect on other trading days. The AR_GARCH $(1,1)$ result shows that the slope of Monday 0.0288 is significant at $1 \%$ level, which signifies that on Monday the VIX value increased by $2.8 \%$ on the previous close. This increase of VIX value by $2.8 \%$ on market opening indicates the investors fear on Monday. The options traders can use this information and sell the options at a high premium price. Due to fear and uncertainty in the market conditions, 
ISSN 2349-2325 (Online); DOI: 10.16962/EAPJFRM/issn. 2349-2325/2015; Volume 9 Issue 2 (2018)

investors bid higher price put/call options. The results for Tuesday shows negative but not significant. The estimated slope is continuously falling from Tuesday to Friday. The result signifies that the VIX holds significant Monday effect and it is positive. The model also estimated the behavior of expected volatility near the expiration dates of European options. In case of European options, investors exercise their options on the expiration date, if it is profitable to exercise. Hence, the expected volatility of the market is high during European option expiration date. The estimated slope coefficient is -0.045 which is significant. The result indicates that the day of European one-month option expiration VIX falls significantly by $4.5 \%$. There is no significant change in the VIX before or after the expiration date. The slope coefficient of $\pi_{1}$ and $\pi_{2}$ are statistically significant and it indicates the volatility persistence in the VIX returns series during the selected sample period. LB-Q (1 2) and $\mathrm{LB}-\mathrm{Q}^{2}\left(\begin{array}{l}1 \\ 1\end{array}\right)$ confirms that the results are free from autocorrelation. The results support the hypothesis that the VIX data has seasonal anomalies. This result will help the investors to hedge the risk by volatility trading.

Table 3 presents the results of Month-of-the year effect. Stock markets are sensitive to corporate results. Corporates declare their results quarterly, Q1(July), Q2 ( October), Q3 (January ) and Q4 (January). So the estimated slope coefficients should be negative and significant during these months. The slope of March (-0.0065) and December (-0.0092) are negative and statistically significant. This shows that the investors are very specific about Q3 and Q4 corporate results. The slope coefficient of June (0.0063) is positive and significant, it implies that investors are more uncertain about Q1 corporate results, hence they buy more to manage the risk. Finally, estimated results supported that the Indian VIX holds seasonal anomalies. (Ref Table 2) \& (Ref Table 3)

Figure 1 shows that stock returns and volatility are negatively related. The volatility is due to lower nifty returns. The figure1 depicts stock negative association between stock returns and volatility.

Table 4 shows the estimates of the equation 7, the OLS estimate of Nifty 50 and India VIX shows the asymmetric relationship between Indian VIX and its underlying index Nifty 50 returns. The estimated coefficient of Nifty 50 returns is 65.56, which is statistically significant. It implies that the benchmark index Nifty 50 and India VIX are negatively correlated. The estimated coefficient for absolute returns of Nifty is 36.79 and is statistically significant, implying that irrespective of the sign of Nifty returns, the expected market volatility increases. The oneday lag Nifty 50 returns have positive and significant effect on Indian VIX, which indicates 
ISSN 2349-2325 (Online); DOI: 10.16962/EAPJFRM/issn. 2349-2325/2015; Volume 9 Issue 2 (2018)

that Nifty 50 one period returns have a positive impact on Indian VIX. The results are supporting the empirical evidence. The result also supports the asymmetric relation between stock returns and volatility. Hence, Indian VIX can be used as a measure of investors fear. (Ref Table 4)

\section{CONCLUSION:}

The empirical tests have been conducted for the period ranging from $2^{\text {nd }}$ March 2009 to $27^{\text {th }}$ March 2018. Results of the study show that the Indian VIX exhibits seasonal anomalies like options expiration date effect, day-of-the-week effect and month-of-the-year effects. The result shows significant positive Monday effect on Indian VIX which implies that the market volatility increases on the opening day of the market and subsequently falls. Another finding of this study reports that there is a significant fall in the expected market volatility on the options expiration date. The month-of-the-year effect shows that March and December have a significant negative impact on expected market volatility and June has a positive impact on expected market volatility. It shows evidence that corporate announcements have some impact on expected market volatility. Understanding the seasonal anomalies will help the volatility traders while pricing the options.

OLS regression estimate confirms that a significant negative association persists between stock return and volatility. The result shows that a negative stock returns has a significant positive effect on market volatility. During negative returns investors are nervous and it results in increased market volatility. These fearful investors buy put options to hedge their portfolios during market negative returns.

\section{REFERENCES:}

1. Aggarwal, R.; Rivoli, P. 1989. Seasonal and dayof-the-week effects in four emerging stock markets, Financial Review 24(4): 541-550

2. Badshah, I. U. (2011). Return-volatility relationships: cross-country evidence. International Journal of Behavioral Accounting and Finance, 2(2), 178 - 190.

3. Badshah, I. U., Frijns, B., \& Tourani-Rad, A. (2013). Contemporaneous Spill-Over Among Equity, Gold, and Exchange Rate Implied Volatility Indices. Journal of Futures Markets, 33(6), 555-572.

4. Balaban, E.; Asli, B.; Kan, Ö. B. 2001. Stock returns, seasonality and asymmetric conditional volatility in world equity markets, Applied Economics Letters 8(4): 263-268

5. Cross, F. 1973. The behavior of stock prices on Fridays and Mondays, Financial Analysts Journal 29(6): 67-69. http://dx.doi.org/10.2469/faj.v29.n6.67 
ISSN 2349-2325 (Online); DOI: 10.16962/EAPJFRM/issn. 2349-2325/2015; Volume 9 Issue 2 (2018)

6. Dhanaiah, G., Reddy, D. R., \& Prasad, T. N. L. (2012). India VIX: Examining the negative and asymmetric volatility index - market return relationship. India Journal of Finance, 6(5), 410.

7. Dowling, S.; Muthuswamy, J. 2005. The implied volatility of Australian index options, Review of Futures Markets 14(1): 117-155

8. Fleming, J.; Ostdiek, B.; Whaley, R. E. 1995. Predicting stock market volatility: a new measure, Journal of Futures Markets 15(3): 265302. http://dx.doi.org/10.1002/fut.3990150303

9. Fleming, J.; Ostdiek, B.; Whaley, R. E. 1995. Predicting stock market volatility: a new measure, Journal of Futures Markets 15(3): 265302

10. Fleming, J.; Ostdiek, B.; Whaley, R. E. 1995. Predicting stock market volatility: a new measure, Journal of Futures Markets 15(3): 265302

11. French, K. R. 1980. Stock returns and the weekend effect, Journal of Financial Economics 8(1): 55-69. http://dx.doi.org/10.1016/0304405X(80)90021-5

12. Gibbons, M. R.; Hess, P. 1981. Day of the week effects and asset returns, Journal of Business 54(4): 579-596.

13. Giot, P. (2002). The information content of implied volatility indexes for forecasting volatility and market risk. Available at SSRN 362440 .
14. Gultekin, M. N.; Gultekin, N. B. 1983. Stock market seasonality: International evidence, Journal of Financial Economics 12(4):

15. Hibbert, A. M., Daigler, R. T., \& Dupoyet, B. (2008). A behavioral explanation for the negative asymmetric return-volatility relation. Journal of Banking \& Finance, 32(10), 2254-2266

16. Imlak Shaikh.,\& Puja Padhi(2015). On the Relationship of Ex-ante and Ex-post Volatility: A Sub-period Analysis of S\&P CNX Nifty Index Options, Journal of Emerging Market Finance August 2015 vol. 14 no. 2 140-175

17. Jaffe, J.; Westerfield, R. 1985. The weekend effect in common stock returns: The international evidence, The Journal of Finance 40(2): 433454.

18. Keim, D. B. 1983. Sizerelated anomalies and stock return seasonality: Further empirical evidence, Journal of Financial Economics 12(1): 13-32.

19. Keim, D. B.; Stambaugh, R. F. 1984. A further investigation of the weekend effect in stock returns, The Journal of Finance 39(3): 819-835.

20. Konstantinidia, E. \& G. Skiadopoulos. 2011. "Are VIX futures prices predictable? An empirical investigation." International Journal of Forecasting 27(2):543-560.

21. Lakonishok, J.; Levi, M. 1982. Weekend effects on stock returns: a note, The Journal of Finance 37(3): 883-889. 
ISSN 2349-2325 (Online); DOI: 10.16962/EAPJFRM/issn. 2349-2325/2015; Volume 9 Issue 2 (2018)

22. Pandey, I. M. 2002. Is there seasonality in the Sensex monthly returns? Working paper. Indian Institute of Management Ahmedabad, 1-17

23. Rozeff, M. S.; Kinney, W. R. 1976. Capital market seasonality: The case of stock returns, Journal of Financial Economics 3(4): 379-402

24. Schwert, G. W. 1989. Why does stock market volatility change over time?, Journal of Finance 44(5): 1115-1153.

25. Schwert, G. W. 1990. Stock volatility and the crash of '87, Review of Financial Studies 3(1): 77-102.

26. Shaikh, I.; Padhi, P. 2014a. Intertemporal relationship between India VIX and NIFTY,
Decision

41(4):

$439-448$.

http://dx.doi.org/10.1007/s40622-014-0046-0

27. Tong, W. H. 1992. An analysis of the January effect of United States, Taiwan and South Korean stock returns, Asia Pacific Journal of Management 9(2): 189-207

28. Whaley, R. E. (2000). The Investor Fear Gauge. The Journal of Portfolio Management, 26(3), $12-17$. https://doi.org/10.39

05/jpm.2000.319728

29. Whaley, Robert E., Understanding VIX (November 6, 2008). Available at SSRN: https://ssrn.com/abstract=1296743 or htt p://dx.doi.org/10.2139/ssrn.1296743

\section{LIST OF TABLES}

\section{Table1: Descriptive statistics of IVIX and IVIX returns}

\begin{tabular}{|l|l|l|}
\hline Statistics & VIX close & VIX returns \\
\hline Mean & 20.1318 & -0.07321 \\
\hline SD & 7.613361 & 0.0693 \\
\hline$\rho_{1}$ & & $-0.360^{*}$ \\
\hline$\rho_{2}$ & & $0.025^{* *}$ \\
\hline$\rho_{3}$ & & $-0.097^{*}$ \\
\hline ARCH(1) & & $456.32^{*}$ \\
\hline ARCH(2) & & $236.23^{* *}$ \\
\hline ARCH(3) & & $352.02^{*}$ \\
\hline Maximum & 62.05 & \\
\hline Minimum & 10.4475 & \\
\hline
\end{tabular}


Table1 reports descriptive statistics for Indian VIX close and Indian VIX returns series. The Autocorrelation coefficient $\rho$ and ARCH-LM test results up to three lags were reported. * indicates that the coefficient is significant at $5 \%$. ** indicate the coefficients are significant at $10 \%$.

Table 2: Estimation of Day-of-the-week and options expiration effect

\begin{tabular}{|c|c|c|c|c|}
\hline \multirow{2}{*}{ Variables } & \multicolumn{2}{|c|}{ AR-DOLS } & \multicolumn{2}{|c|}{ AR-GARCH $(1,1)$} \\
\hline & Estimate & $\mathrm{p}$-value & Estimate & $p$-value \\
\hline & 0.0358 & 0.000 & 0.0288 & 0.000 \\
\hline$\alpha_{2}$ & -0.0051 & 0.3251 & -0.0122 & 0.1443 \\
\hline$\alpha_{3}$ & -0.0025 & 0.7458 & -0.0056 & 0.1227 \\
\hline$\alpha_{4}$ & 0.0012 & 0.2586 & 0.0037 & 0.2256 \\
\hline$\alpha_{5}$ & -0.0125 & 0.5214 & -0.0026 & 0.1975 \\
\hline$\delta_{-2}$ & -0.0145 & 0.1263 & -0.0032 & 0.4532 \\
\hline$\delta_{-1}$ & -0.0251 & 0.2236 & 0.0022 & 0.2608 \\
\hline$\delta_{0}$ & -0.0452 & 0.000 & -0.0328 & 0.0001 \\
\hline$\delta_{1}$ & -0.0175 & 0.4582 & -0.0125 & 0.7524 \\
\hline$\delta_{2}$ & -0.0201 & 0.4125 & -0.0256 & 0.0345 \\
\hline$\gamma$ & -0.1256 & 0.0000 & -0.0446 & 0.0278 \\
\hline$\pi_{1}$ & & & 0.3412 & 0.000 \\
\hline$\pi_{2}$ & & & 0.6152 & 0.000 \\
\hline Adj. $R^{2}$ & 0.07 & & 0.08 & \\
\hline LB-Q (1 2) & & & $14.41(0.046)$ & \\
\hline
\end{tabular}


$*$ indicates $1 \%$ level significance, $* *$ indicates $5 \%$ level significance, $* * *$ indicates $10 \%$ level significance.

Table3: AR-DOLS and AR-GARCH estimated values for Month-of-the year effect

\begin{tabular}{|c|c|c|c|c|}
\hline \multirow{2}{*}{ Variables } & \multicolumn{2}{|c|}{ AR-DOLS } & \multicolumn{2}{|c|}{ AR-GARCH $(1,1)$} \\
\hline & Estimate & $\mathrm{p}$-value & Estimate & $\mathrm{p}$-value \\
\hline$\varphi_{1}$ & 0.0080 & 0.1254 & 0.0011 & 0.6832 \\
\hline$\varphi_{2}$ & -0.0042 & 0.2542 & 0.0394 & 0.5536 \\
\hline$\varphi_{3}$ & -0.0044 & 0.2355 & -0.0065 & 0.0025 \\
\hline$\varphi_{4}$ & -0.0045 & 0.5896 & -0.0092 & 0.5293 \\
\hline$\varphi_{5}$ & 0.0033 & 0.6485 & 0.0033 & 0.2156 \\
\hline$\varphi_{6}$ & 0.0056 & 0.4059 & 0.0063 & 0.0125 \\
\hline$\varphi_{7}$ & -0.0021 & 0.5236 & 0.0016 & 0.2131 \\
\hline$\varphi_{8}$ & -0.0011 & 0.4521 & 0.0052 & 0.5123 \\
\hline$\varphi_{9}$ & 0.0008 & 0.3365 & -0.0050 & 0.1461 \\
\hline$\varphi_{10}$ & 0.0004 & 0.7693 & -0.0050 & 0.2396 \\
\hline$\varphi_{11}$ & -0.0010 & 0.6789 & -0.0011 & 0.1352 \\
\hline$\varphi_{12}$ & -0.0043 & 0.0180 & -0.0092 & 0.0155 \\
\hline$\gamma$ & -0.2151 & 0.0000 & -0.0894 & 0.0000 \\
\hline$\pi_{1}$ & & & 0.5508 & 0.0000 \\
\hline$\pi_{2}$ & & & 0.6895 & 0.0000 \\
\hline Adj. $R^{2}$ & 0.04 & & 0.08 & \\
\hline LB-Q ( $\left(\begin{array}{ll}1 & 2\end{array}\right)$ & & & $23.03(0.031)$ & \\
\hline $\mathrm{LB}-\mathrm{Q}^{2}\left(\begin{array}{ll}1 & 2\end{array}\right)$ & & & 6.18 (0.904) & \\
\hline
\end{tabular}


ISSN 2349-2325 (Online); DOI: 10.16962/EAPJFRM/issn. 2349-2325/2015; Volume 9 Issue 2 (2018)

Bold indicates the coefficients are significant at $1 \%, 5 \%$ and $10 \%$ level of significanc

Table 4: OLS estimates of Nifty 50 and India VIX

\begin{tabular}{|l|l|l|}
\hline & Estimated value & T Statistic \\
\hline Intercept & -0.318 & $7.89 *$ \\
\hline Nifty 50 lag 2 & -0.286 & -0.56 \\
\hline Nifty50 lag 1 & 28.26 & $6.63^{*}$ \\
\hline Nifty 50 returns & -65.56 & $8.96^{*}$ \\
\hline Nifty 50 lead returns1 & 0.096 & 0.23 \\
\hline Nifty50 Lead returns 2 & -3.569 & 0.42 \\
\hline Nifty 50 abs Returns & 36.79 & 5.51 \\
\hline Adj. R & & \\
\hline F-statistic & 0.41 & \\
\hline DW-stat & $89.95^{*}$ & \\
\hline
\end{tabular}

*Indicates that the values are statistically significant

\section{LIST OF FIGURES}

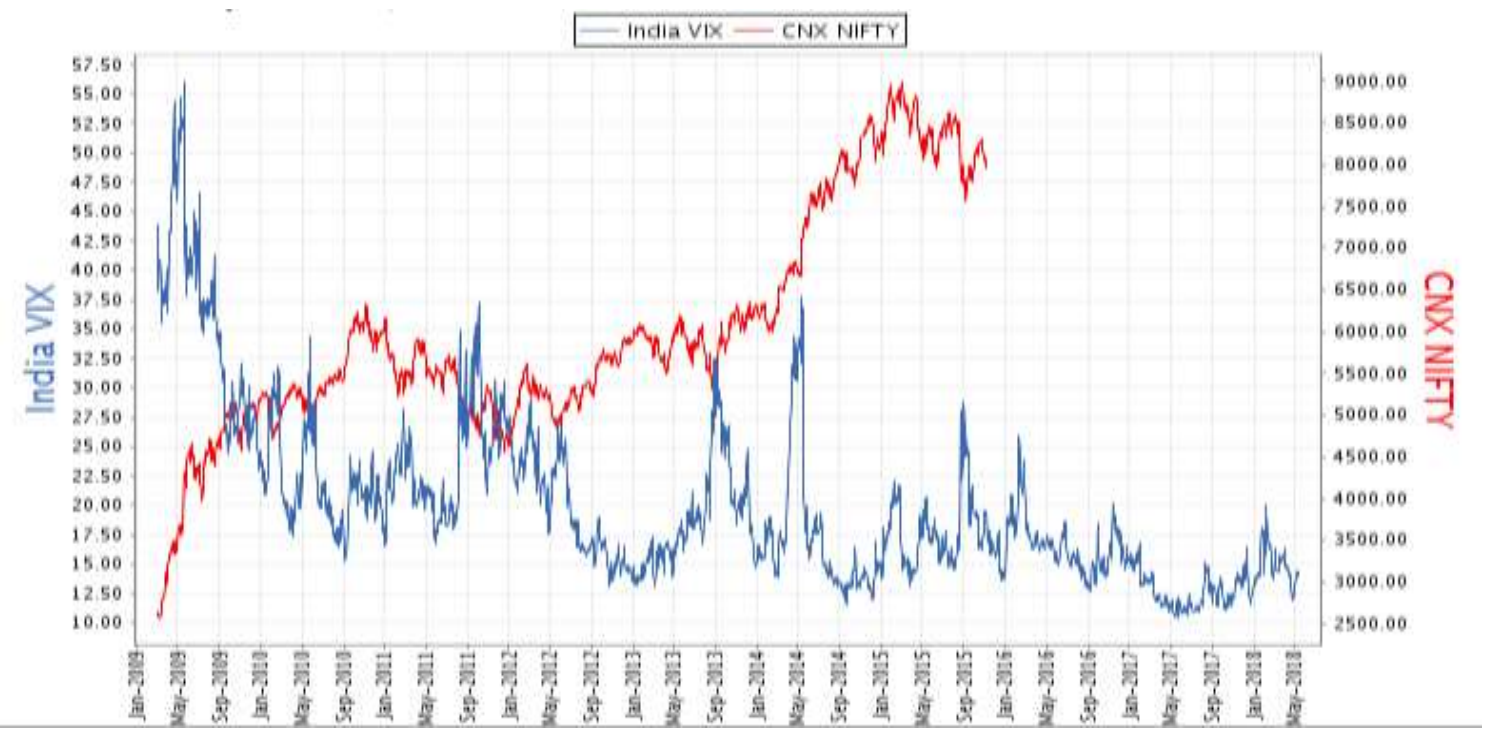

Figure 1: India VIX and CNX Nifty co0-movements chart. 